Research article Open Access

\title{
Predictors of the first cardiovascular event in patients with systemic lupus erythematosus - a prospective cohort study
} Johanna Gustafsson ${ }^{1}$, Iva Gunnarsson ${ }^{1}$, Ola Börjesson ${ }^{1}$, Susanne Pettersson ${ }^{1}$, Sonia Möller ${ }^{1}$, Guo-Zhong Fei ${ }^{1}$, Kerstin Elvin ${ }^{2}$, Julia F Simard ${ }^{3}$, Lars-Olof Hansson ${ }^{4}$, Ingrid E Lundberg ${ }^{1}$, Anders Larsson ${ }^{5}$ and Elisabet Svenungsson ${ }^{1}$

\author{
${ }^{1}$ Rheumatology Unit, Department of Medicine Karolinska University Hospital, Solna, Karolinska Institutet, SE-171 76 Stockholm, Sweden \\ 2Unit of Clinical Immunology, Department of Clinical Immunology and Transfusion Medicine, Karolinska University Hospital, Karolinska Institutet, SE- \\ 17176 Stockholm, Sweden \\ ${ }^{3}$ Clinical Epidemiology Unit, Karolinska Institutet, SE-171 76 Stockholm, Sweden \\ ${ }^{4}$ Department of Laboratory Medicine, Karolinska University Hospital, Karolinska Institutet, SE-171 76 Stockholm, Sweden \\ ${ }^{5}$ Department of Clinical Chemistry and Pharmacology, Akademiska Hospital, SE-751 85 Uppsala, Sweden \\ Corresponding author: Elisabet Svenungsson, Elisabet.Svenungsson@ki.se
}

Received: 13 Sep 2009 Revisions requested: 5 Nov 2009 Revisions received: 20 Nov 2009 Accepted: 10 Dec 2009 Published: 10 Dec 2009

Arthritis Research \& Therapy 2009, 11:R186 (doi:10.1186/ar2878)

This article is online at: http://arthritis-research.com/content/11/6/R186

(c) 2009 Gustafsson et al.; licensee BioMed Central Ltd.

This is an open access article distributed under the terms of the Creative Commons Attribution License (http://creativecommons.org/licenses/by/2.0), which permits unrestricted use, distribution, and reproduction in any medium, provided the original work is properly cited.

\begin{abstract}
Introduction Cardiovascular disease (CVD) is a major cause of premature mortality among Systemic lupus erythematosus (SLE) patients. Many studies have measured and evaluated risk factors for premature subclinical atherosclerosis, but few studies are prospective and few have evaluated risk factors for hard endpoints, i.e. clinically important cardiovascular events (CVE). We investigated the impact of traditional and lupus associated risk factors for the first ever CVE in a longitudinal cohort of SLE patients.
\end{abstract}

Methods A total of 182 SLE patients (mean age 43.9 years) selected to be free of CVE were included. Cardiovascular and autoimmune biomarkers were measured on samples collected after overnight fasting at baseline. Clinical information was collected at baseline and at follow up. End point was the first ever CVE (ischemic heart, cerebrovascular or peripheral vascular disease or death due to CVD). Impact of baseline characteristics/biomarkers on the risk of having a first CVE was evaluated with Cox regression.
Results Follow up was $99.5 \%$ after a mean time of 8.3 years. Twenty-four patients (13\%) had a first CVE. In age-adjusted Cox regression, any positive antiphospholipid antibody (aPL), elevated markers of endothelial activation (von Willebrand factor (vWf), soluble vascular cellular adhesion molecule-1 (sVCAM1)) and fibrinogen predicted CVEs. Of SLE manifestations, arthritis, pleuritis and previous venous occlusion were positively associated with future CVEs while thrombocytopenia was negatively associated. Among traditional risk factors only age and smoking were significant predictors. In a multivariable Cox regression model age, any positive aPL, vWf and absence of thrombocytopenia were all predictors of the first CVE.

Conclusions In addition to age, positive aPL, biomarkers indicating increased endothelial cell activity/damage, and absence of thrombocytopenia were independent predictors of CVEs in this prospective study. Our results indicate that activation of the endothelium and the coagulation system are important features in SLE related CVD. Furthermore, we observed that the risk of CVEs seems to differ between subgroups of SLE patients.

aCL: anticardiolipin antibodies; ANA: antinuclear antibodies; ApoB/ApoA: apolipoproteinB/A; APS: anti-phospholipid syndrome; aPL: antiphospholipid antibody; $\beta_{2}$ GP1: $\beta_{2}$-glycoprotein 1 ; C: complement factor; C3d: complement factor 3 degradation products; CAD: coronary artery disease; Cl: confidence interval; CVD: cardiovascular disease; CVE: cardiovascular event; dsDNA: anti-double-stranded DNA; ELISA: enzyme-linked immunosorbent assays; GPL/MPL: standardized unit used for measuring anticardiolipin antibodies (one unit approximated to $1 \mathrm{~g}$ of immunoglobulin G (IgG) (for GPL) or lgM (for MPL) anticardiolipin antibody purified from $1 \mathrm{~mL}$ of serum.); HDL: high density lipoprotein; HR: hazard ratio; HRP: horseradish peroxidase; hsCRP: high sensitivity C reactive protein; ICVD: ischemic cerebrovascular disease; IFL: immunofluorescence; IHD: ischemic heart disease; IL-6: interleukin 6; IPVD: ischemic peripheral vascular disease; LAC: lupus anticoagulant; LDL: low density lipoprotein; MDRD: estimated glomerular filtration rate using the Modification of Diet in Renal Disease formula; RNP: ribonucleoprotein; SAA: serum amyloid A; SLAM: systemic lupus activity measure; SLE: systemic lupus erythematosus; SLICC: systemic lupus international collaborating clinics damage index; Sm: Smith; SSA/ SSB: Sjögren's syndrome A and B; sVCAM-1: soluble vascular cell adhesion molecule 1; vWf: von Willebrand factor. 


\section{Introduction}

Systemic lupus erythematosus (SLE) is a heterogeneous chronic systemic autoimmune disease, which mainly affects women (90\%). As treatment for lupus itself has gradually improved, mortality rates have declined and cardiovascular comorbidity has become a growing clinical problem. Circulatory diseases are today a leading cause of mortality among SLE patients $[1,2]$.

Traditional coronary artery disease (CAD) risk factors are more prevalent among SLE patients than in the general population $[3,4]$ but they do not alone account for the high incidence of premature cardiovascular disease (CVD) seen in SLE $[5,6]$. Additionally, several SLE associated risk factors have been identified such as pro-thrombotic antiphospholipid antibodies (aPL) $[4,7,8]$, accelerated endothelial cell apoptosis and impaired repair of damaged endothelium $[9,10]$, oxidized low density lipoprotein (LDL) [11], pro-inflammatory high density lipoprotein (HDL) [12], genetic susceptibility [13] and decreased endothelial binding of annexin V [14]. The role of these and other mechanisms for premature cardiovascular morbidity and mortality seen in SLE are presently under intense study by many research groups.

Prospective studies that evaluate both traditional and lupus associated risk factors for hard endpoints, that is, CVEs, are to date relatively few in SLE $[8,15,16]$ and outnumbered by studies focused on subclinical atherosclerosis in these patients $[4,17,18]$. But, measurements of atherosclerosis are surrogate markers of CVD and given the complexity of SLE, accelerated atherosclerosis may not be the only biologically plausible connection to CVEs. Other factors in an immunologically active setting like SLE may influence the likelihood of CVEs. It is therefore important to perform longitudinal studies in well-characterized SLE patients and to use hard endpoints such as myocardial infarction and stroke.

In a single center cohort of SLE patients, we selected patients free from clinical CVD and investigated the impact of traditional CAD risk factors, lupus associated biomarkers and clinical manifestations/features on the risk of presenting with a first ever CVE during eight years of follow-up.

\section{Materials and methods Patients}

All SLE patients at the Department of Rheumatology, Karolinska University Hospital who fulfilled four or more of the 1982 revised American College of Rheumatology Criteria for classification of SLE [19] during the inclusion period (1995-99) were asked to participate. A total of 182 of 208 (87.5\%) participants were free of previous CVEs and were included in this study. $94 \%$ of the patients were European Caucasians and six percent were of Asian origin.
At follow-up (2004-2007) living patients were reinvestigated in person when possible. If not, they were interviewed by telephone. Medical charts were reviewed for all patients and death certificates were collected from all deceased patients. Autopsy protocols were collected when available. The Local Ethics Committee of the Karolinska University Hospital approved the study. All patients gave informed consent to participate.

\section{Data collection}

At baseline, patients were interviewed and examined by a rheumatologist who evaluated disease activity using Systemic Lupus Activity Measure (SLAM) [20] and organ damage with Systemic Lupus International Collaborating Clinics damage index (SLICC) [21]. A SLAM score $>6$ was considered as active disease [22]. Blood samples were taken after overnight fasting and laboratory examinations were performed blinded, either on fresh blood samples or after storage in $-70^{\circ} \mathrm{C}$. When stored samples were used (see Table 1), all samples were frozen and each investigation was carried out in one session.

\section{Outcome measures of CVE}

CVE were defined as: 1) Ischemic heart disease (IHD): myocardial infarction (Ml, confirmed by electrocardiography and a rise in plasma creatine kinase, muscle and brain fraction (CK$\mathrm{MB}$ ) or troponin $\mathrm{T}$ ) or angina pectoris (confirmed by exercise stress test).

2) Ischemic cerebrovascular disease (ICVD): cerebral infarction (confirmed by computer tomography) or transitory ischemic attacks (TIA, defined as transient focal symptoms from the brain or retina with a maximum duration of 24 hours).

3) Ischemic peripheral vascular disease (IPVD): intermittent claudication or peripheral arterial thrombosis/embolus (confirmed by angiogram or Doppler flow studies).

4) Death due to ischemic vascular disease: death due to myocardial infarction, heart failure, sudden death, cerebral infarction, generalized atherosclerosis as stated by death certificate.

\section{Laboratory Methods}

High sensitivity C-reactive protein (CRP), $\alpha-1$ antitrypsine, fibrinogen and Serum Amyloid A (SAA) were measured using BN ProSpec System (Dade Behring, Deerfield, IL, USA). C3 and $\mathrm{C} 4$ were analyzed using IMMAGE ${ }^{\mathrm{TM}}$ and $\mathrm{C} 3 \mathrm{~d}$ using an ARRAY ${ }^{\text {TM }}$ system (both instruments are from Beckman Coulter, Brea, CA, USA). Albumin, apolipoprotein A1, apolipoprotein $B$ and homocysteine were measured on an Architect Ci8200 analyzer (Abbott Laboratories, Abbott Park, IL, USA).

Enzyme-linked immunosorbent assays (ELISA) were used to measure Vascular cell adhesion molecule (VCAM-1, DY809, R\&D Systems, Minneapolis, MN, USA), vWF (antisera from Dako (Glostrup, Denmark) calibrated against Liatest (Diagnos- 
Table 1

\begin{tabular}{|c|c|c|c|c|}
\hline & $\begin{array}{l}\text { All patients } \\
\mathrm{N}=182\end{array}$ & $\begin{array}{l}\text { Patients who developed CVE } \\
\mathrm{N}=24\end{array}$ & $\begin{array}{l}\text { Patients free of CVE } \\
\mathrm{N}=158\end{array}$ & $P$ \\
\hline \multicolumn{5}{|l|}{ Traditional risk factors } \\
\hline Age years & $45(31-53)$ & 59 (49 to 66$)$ & $44(30-52)$ & $<0.0001$ \\
\hline Male gender & $10 \%$ & $9 \%$ & $11 \%$ & \\
\hline Smoking ever & $51 \%$ & $70 \%$ & $46 \%$ & 0.02 \\
\hline Hypertension & $30 \%$ & $42 \%$ & $28 \%$ & \\
\hline Systolic blood pressure $(\mathrm{mmHg})^{*}$ & 125 (115 to 140$)$ & 140 (120 to 143$)$ & $120(110$ to 140$)$ & 0.03 \\
\hline Hypercholestrolemia & $41 \%$ & $54 \%$ & $39 \%$ & \\
\hline Total cholesterol (mmol/L) & 4.9 (4.3 to 5.9$)$ & $5.7(4.5$ to 6.4$)$ & $4.9(4.2$ to 5.7$)$ & 0.05 \\
\hline $\mathrm{LDL}(\mathrm{mmol} / \mathrm{L})$ & 2.8 (2.3 to 3.5$)$ & $3.0(2.7$ to 4.0$)$ & 2.8 (2.2 to 3.5$)$ & \\
\hline $\mathrm{HDL}(\mathrm{mmol} / \mathrm{L})$ & $1.4(1.1$ to 1.7$)$ & $1.3(1.0$ to 1.9$)$ & $1.4(1.1$ to 1.7$)$ & \\
\hline Triglycerides $(\mathrm{mmol} / \mathrm{L})^{\star}$ & $1.3(1.0$ to 1.9$)$ & 1.5 (1.2 to 2.0$)$ & 1.2 (0.9 to 1.9 ) & \\
\hline ApoB/ApoA* + & 0.5 (0.3 to 0.6$)$ & $0.6(0.4$ to 0.8$)$ & 0.5 (0.3 to 0.6$)$ & \\
\hline Diabetes & $2 \%$ & $0 \%$ & $2 \%$ & \\
\hline \multicolumn{5}{|l|}{ Lupus manifestations } \\
\hline Disease duration & $10(4$ to 18$)$ & 18 (10 to 24$)$ & $10(4$ to 17$)$ & 0.0005 \\
\hline Malar rash & $58 \%$ & $58 \%$ & $58 \%$ & \\
\hline Discoid rash & $22 \%$ & $22 \%$ & $22 \%$ & \\
\hline Photosensitivity & $71 \%$ & $50 \%$ & $75 \%$ & 0.01 \\
\hline Oral ulcers & $29 \%$ & $37 \%$ & $27 \%$ & \\
\hline Arthritis & $84 \%$ & $100 \%$ & $82 \%$ & 0.02 \\
\hline Pleuritis & $38 \%$ & $65 \%$ & $34 \%$ & 0.005 \\
\hline Pericarditis & $18 \%$ & $17 \%$ & $22 \%$ & \\
\hline Nephritis & $30 \%$ & $37 \%$ & $29 \%$ & \\
\hline Neurological disorder & $12 \%$ & $17 \%$ & $11 \%$ & \\
\hline Leucopenia & $56 \%$ & $57 \%$ & $46 \%$ & \\
\hline Thrombocytopenia & $21 \%$ & $4 \%$ & $24 \%$ & 0.03 \\
\hline Previous venous occlusion & $12 \%$ & $29 \%$ & $9 \%$ & 0.004 \\
\hline SLICC $>1$ & $53 \%$ & $79 \%$ & $49 \%$ & 0.006 \\
\hline SLAM $>6$ at baseline & $45 \%$ & $50 \%$ & $44 \%$ & \\
\hline \multicolumn{5}{|l|}{ Medication } \\
\hline Months on steroid treatment ${ }^{\star}$ & 35 (3 to 118$)$ & 54 (1 to 123$)$ & 31 (3 to119) & \\
\hline Cyclofosfamide treatment ever & $15 \%$ & $8 \%$ & $16 \%$ & \\
\hline Azathioprine at baseline & $38 \%$ & $4 \%$ & $33 \%$ & \\
\hline Chloroquine/Hydroxychloroquine at baseline & $29 \%$ & $21 \%$ & $30 \%$ & \\
\hline Warfarin at baseline & $9 \%$ & $13 \%$ & $8 \%$ & \\
\hline ASA at baseline & $19 \%$ & $25 \%$ & $18 \%$ & \\
\hline Statins at baseline & $0.6 \%$ & $0 \%$ & $0.7 \%$ & \\
\hline
\end{tabular}

Autoantibodies against 
Table 1 (Continued)

\section{Baseline characteristics of patients}

\begin{tabular}{|c|c|c|c|c|}
\hline dsDNA & $36 \%$ & $33 \%$ & $36 \%$ & \\
\hline CL lgG & $47 \%$ & $58 \%$ & $46 \%$ & \\
\hline CL lgM & $15 \%$ & $21 \%$ & $14 \%$ & \\
\hline$\beta_{2} \mathrm{GP}-1 \mathrm{lgG}+$ & $36 \%$ & $54 \%$ & $34 \%$ & 0.05 \\
\hline Lupus anticoagulant & $21 \%$ & $25 \%$ & $20 \%$ & \\
\hline any PL & $65 \%$ & $83 \%$ & $63 \%$ & 0.05 \\
\hline SSA & $43 \%$ & $25 \%$ & $46 \%$ & \\
\hline SSB & $24 \%$ & $13 \%$ & $25 \%$ & \\
\hline $\mathrm{Sm}$ & $11 \%$ & $8 \%$ & $12 \%$ & \\
\hline RNP & $11 \%$ & $14 \%$ & $11 \%$ & \\
\hline \multicolumn{5}{|c|}{ Markers of systemic inflammation } \\
\hline hs CRP (mg/L)† & $1.9(0.7$ to 5.1$)$ & $4.9(1.7$ to 23.5$)$ & $1.7(0.6$ to 4.1$)$ & 0.0002 \\
\hline Fibrinogen $(\mathrm{g} / \mathrm{L})^{\star}+$ & 3.4 (2.9 to 4.5$)$ & 4.6 (3.3 to 5.3$)$ & 3.2 (2.8 to 4.3$)$ & 0.002 \\
\hline$\alpha-1$ antitrypsine $(g / L) \dagger$ & 1.5 (1.3 to 1.7$)$ & $1.8(1.4$ to 2.2$)$ & 1.5 (1.3 to 1.7 & 0.002 \\
\hline $\mathrm{SAA}(\mathrm{mg} / \mathrm{L})^{\star}+$ & $5.0(2.5$ to 10.9$)$ & 9.3 (5.1 to 26.8$)$ & 4.5 (2.3 to 9.3 & 0.004 \\
\hline IL $6(n g / L){ }^{*}+$ & $3.3(2.0$ to 6.9$)$ & $5.3(2.7$ to 10.9$)$ & $3.1(1.9$ to 6.4$)$ & 0.03 \\
\hline C3 $(g / L) \dagger$ & $1.0(0.8$ to 1.2$)$ & 1.0 (0.9 to 1.3$)$ & $1.0(0.8$ to 1.2$)$ & \\
\hline C3d $(\mathrm{mg} / \mathrm{L}) \dagger$ & $\begin{array}{l}11.8 \\
(9.6 \text { to } 14.7)\end{array}$ & $\begin{array}{l}12.9 \\
(10.5 \text { to } 15.9)\end{array}$ & $\begin{array}{l}11.6 \\
(9.5 \text { to } 14.5)\end{array}$ & \\
\hline $\mathrm{C} 4(\mathrm{~g} / \mathrm{L}) \dagger$ & $0.1(0.1$ to 0.2$)$ & 0.1 (0.09 to 1.4$)$ & 0.1 (0.1 to 0.2$)$ & \\
\hline \multicolumn{5}{|c|}{ Markers of endothelial activation } \\
\hline sVCAM-1 (ng/L)*† & 306 (252 to 385$)$ & 373 (303 to 503) & 302 (249 to 375$)$ & 0.0009 \\
\hline von Willebrand factor \%*† & 117 (61 to 166$)$ & 157 (114 to 232$)$ & 112 (59 to 158$)$ & 0.001 \\
\hline \multicolumn{5}{|l|}{ Markers of renal damage } \\
\hline Creatinine $(\mu \mathrm{mol} / \mathrm{L})^{*}$ & $82(73$ to 94$)$ & 87 (76 to 107$)$ & 81 (72 to 93$)$ & 0.01 \\
\hline MDRD ml/min/1.73 $\mathrm{m}^{2}$ & $68(57$ to 80$)$ & $59(45$ to 71$)$ & $69(58$ to 81$)$ & 0.004 \\
\hline Blood urea nitrogen mmol/L† & $5.7(4.7$ to 7.2$)$ & $6.5(5.3$ to 9.9$)$ & 5.6 (4.6 to 6.8$)$ & 0.01 \\
\hline Pathologic urine & $23 \%$ & $25 \%$ & $22 \%$ & \\
\hline \multicolumn{5}{|l|}{ Other biomarkers } \\
\hline Albumin (g/L) & 45 (41 to 48$)$ & $41(37$ to 45$)$ & 45 (42 to 48$)$ & 0.002 \\
\hline Homocystein $(\mu \mathrm{mol} / \mathrm{L})^{\star}+$ & $12.3(10.0$ to 15.6$)$ & 12.1 (10.4 to 17.9 ) & $12.4(9.8$ to 15.4$)$ & \\
\hline
\end{tabular}

Distributions are given as $\%$ or median (interquartile range). $P$ values, not adjusted for age, $\leq 0.05$ are presented. ${ }^{*}$ indicate not normally distributed variables. + indicate that analyses were done on frozen samples. Hypertension was defined as a systolic blood pressure $>140 \mathrm{~mm} \mathrm{Hg}$ and/or a diastolic blood pressure $>90 \mathrm{mmHg}$ and/or present treatment for hypertension. Hypercholesterolemia was defined as a total cholesterol level $>5.2 \mathrm{mmol} / \mathrm{L}$.

$\beta_{2}$ GP-1 = beta ${ }_{2}$ glykoprotein-1; any $\mathrm{PL}=$ positive antibody test against $\mathrm{CL}$ lgG or lgM, $\beta_{2} \mathrm{GP}-1$ lgG or a positive lupus anticoagulant test; ApoB/ $\mathrm{ApoA}=$ apolipoprotein B/A. Disease manifestations were defined according to the 1982 revised American College of Rheumatology (ACR) criteria for classification of SLE [19]; $\mathrm{C}=$ Complement factor; C3d = Complement factor 3 degradation products; CL = cardiolipin; dsDNA = doublestranded DNA; HDL = high density lipoprotein; hsCRP = high sensitivity $\mathrm{C}$ reactive protein; IL-6 = interleukin 6 ; LDL = low density lipoprotein; MDRD = Estimated glomerular filtration rate using the Modification of Diet in Renal Disease (MDRD) formula [51]. Pathologic urine as defined by SLAM [20]; PL = phospholipid; RNP = r ibonucleoprotein; SAA = serum amyloid A; SLAM = a measure of disease activity [20]; SLICC = a measure of cumulative disease damage [21], Sm = Smith; SSA = Sjogrens syndrome A;

$\mathrm{SSB}=$ Sjogrens syndrome B; sVCAM-1 = soluble vascular cell adhesion molecule 1.

Pathologic urine as defined by SLAM [20]. 
tica Stago, Asnieres, France), intra-assay coefficient of variation were <7\%) and Interleukin 6 (IL-6, high sensitive ELISA, HS600, R\&D Systems, Minneapolis, MN, USA).

Antinuclear antibodies (ANA) were analysed by immunofluorescence on sections of rat liver and HEp-2 cells (Immunoconcepts, Sacramento, CA, USA) and auto-antibodies to Sjögren's syndrome A and B (SSA, SSB), Smith (Sm) and Ribonucloprotein (RNP) using ANA-profile ELISA (Pharmacia Diagnostics, Uppsala, Sweden), Innolia Immunoblot (Innogenetics, N.U. Ghent, Belgium), and Auto Immunodiffusion (Immunoconcepts, Sacramento, CA, USA). Anti-doublestranded DNA (dsDNA) antibodies were determined by IFL using Crithidia lucillae kinetoplast assay (Immunoconcepts, Sacramento, CA, USA). Anticardiolipin antibodies (aCL) were measured by ELISA using ethanol fixed cardiolipin (SigmaAldrich, St Louis, MO, USA) and HRP-conjugated rabbit immunoglobulins against human IgG, respectively IgM (Dako, Glostrup, Denmark). The levels of positivity were calibrated against Harris standard (Louisville, LAPL-GM-001). Low aCL level corresponded to 10-20, medium level to 20-80 and high level to $>80$ GPL/MPL Units. The cut off values for positive aCL was calculated to be at least the $95^{\text {th }}$ percentile of healthy blood donors. Autoantibodies to $\beta_{2}$-glycoprotein1 ( $\beta_{2} \mathrm{GP1}$, $\operatorname{lgG}$ ) were analysed by ELISA (Orgentec, Mainz, Germany). Positive cut-off level was used according to the manufacturer's descriptions. Borderline results were regarded as negative. Lupus anticoagulant (LAC) was determined using a modified Dilute Russel Viper Venom method, (Biopool, Umea, Sweden) using Bioclot LAC.

\section{Statistics}

Patient characteristics were summarized for all patients and by CVE occurrence and were compared using ANOVA, MannWhitney $U$-test and $X^{2}$ test as needed. Log transformation was used for skewed continuous variables. Hazard ratios (HR) and 95\% confidence intervals $(95 \% \mathrm{Cl})$ for the first CVE were calculated in uni- and multivariable-adjusted Cox regression models for baseline factors.

Variables were first sorted into functional groups (traditional risk factors, lupus manifestations etc. see Table 1 and 2). After adjusting for age, the variables within each group, which were representative and most significantly associated with future CVEs were entered into a multivariable-adjusted model. Because of a limited number of first CVEs, we restricted the number of variables in the multivariable-adjusted model to four. Calculations were done using JMP software (SAS Institute, Carey, North Carolina, USA). A $P$ value $<0.05$ was considered statistically significant.

\section{Results}

\section{Baseline data and clinical manifestations}

As expected, patients who developed a first CVE were older, more likely to have ever smoked, have higher total cholesterol levels and to have higher systolic blood pressure. Furthermore, they had a longer mean SLE duration, were more likely to have had previous venous occlusion, pleuritis, arthritis and leucopenia but were less likely to have photosensitivity or thrombocytopenia. Several markers of systemic inflammation, endothelial activation and renal damage, together with aPL, were elevated at baseline in patients who developed a first CVE (Table 1).

\section{Cardiovascular events}

Surviving patients were reinvestigated after a mean time of 8.3 \pm 1.2 years. A total 132 patients were examined in person, and 34 through a structured telephone interview. Fifteen patients were deceased and their death certificates were investigated. Five autopsies had been performed and all protocols were reviewed. Medical files were reviewed for all with the exception of one patient who was unwilling to participate at follow up, thus her history of CVE could not be determined.

Twenty-four new CVEs occurred, three of which were fatal (two heart failures, one atherosclerosis according to death certificates) (Table 3).

\section{Prospective evaluation of risk factors for CVEs}

As expected, age was a strong predictor of the first CVE, we therefore adjusted all measurements for age. Thereafter, only smoking of the traditional risk factors remained as a predictor of CVEs. Of lupus manifestations arthritis, pleuritis, previous venous occlusion and absence of thrombocytopenia were associated with first CVEs. Among biomarkers aPL (aCL IgG, $\beta$ GP1 lgG and any aPL), fibrinogen, markers of endothelial activation (sVCAM-1 and vWf), low levels of plasma albumin, and absence of SSB antibodies remained as predictors of the first CVE. All patients with a first CVE had arthritis, and none had diabetes, therefore these variables could not be further evaluated (Table 2). In a multivariable-adjusted model age, any positive aPL, and $v W f$ were positively associated with CVEs, while thrombocytopenia was inversely associated (Table 4). In an alternative model we exchanged $v W f$ for sVCAM-1. sVCAM remained in this model, together with the other variables in Table 4, as an independent predictor of CVEs (Relative Risk for sVCAM-1 $=2.11,95 \% \mathrm{Cl}(1.24$ to 3.58$), P=0.005)$.

\section{Discussion}

This is, to our knowledge, the first study to investigate predictors of the first ever CVE in SLE and a novel observation is that high levels of endothelial markers precede these events. We also identified SLE manifestations and can confirm [8] occurrence of aPLs as predictors of first CVEs. It is of note that, with the exception of age and smoking, traditional CAD risk factors did not explain CVEs in this study.

In healthy individuals high circulating levels of vWf predicted CVEs in several studies [23,24], but in contrast to this study, significance did not remain after adjustment for other CAD risk factors [24,25]. Myocardial infarctions are common in condi- 
Table 2

Baseline predictors of the first ever cardiovascular event, page-adjusted Cox regression models

\begin{tabular}{|c|c|c|c|}
\hline & Hazard Ratio & 95\% Confidence interval & $P$ \\
\hline \multicolumn{4}{|l|}{ Traditional risk factors } \\
\hline \multirow[t]{2}{*}{ Age univariate } & $2.28^{\star}$ & 1.67 to 2.10 & $<0.0001$ \\
\hline & Age adjusted & & \\
\hline Male gender & 0.71 & 0.11 to 2.41 & \\
\hline Smoking, ever & 2.62 & 1.11 to 7.03 & 0.03 \\
\hline Hypertension & 0.72 & 0.30 to 1.70 & \\
\hline Systolic blood pressure & 0.78 & 0.52 to 1.18 & \\
\hline Hypercholesterolemia & 1.37 & 0.61 to 3.14 & \\
\hline Total cholesterol & 1.19 & 0.81 to 1.74 & \\
\hline LDL & 1.23 & 0.80 to 1.89 & \\
\hline $\mathrm{HDL}$ & 0.77 & 0.34 to 1.62 & \\
\hline Triglyceridest & 1.21 & 0.86 to 1.69 & \\
\hline ApoB/ApoAt & 1.36 & 0.88 to 2.10 & \\
\hline Diabetes & $\neq$ & $\neq$ & 0.02 \\
\hline \multicolumn{4}{|l|}{ Manifestations of Lupus } \\
\hline Disease duration & 1.28 & 0.98 to 1.68 & \\
\hline Malar rash & 1.09 & 0.72 to 1.67 & \\
\hline Discoid lupus & 0.80 & 0.45 to 1.26 & \\
\hline Photosensitivity & 0.69 & 0.46 to 1.04 & \\
\hline Oral ulcers & 1.40 & 0.90 to 2.14 & \\
\hline Arthritis & $\S$ & $\S$ & 0.002 \\
\hline Pleuritis & 1.60 & 1.02 to 2.46 & 0.04 \\
\hline Pericarditis & 1.35 & 0.77 to 2.16 & \\
\hline Nephritis & 1.31 & 0.85 to 1.97 & \\
\hline Leukopenia & 0.94 & 0.62 to 1.42 & \\
\hline Thrombocytpenia & 0.37 & 0.09 to 0.83 & 0.009 \\
\hline Neurologic disorder & 0.78 & 0.48 to 1.44 & \\
\hline Previous venous occlusion & 1.88 & 1.16 to 2.90 & 0.01 \\
\hline SLICC $>1$ & 1.91 & 0.74 to 5.97 & \\
\hline SLAM $>6$ at baseline & 1.25 & 0.83 to 1.87 & \\
\hline \multicolumn{4}{|l|}{ Medications } \\
\hline Months on steroid treatment & 1.00 & 0.68 to 1.48 & \\
\hline Cyclofosfamide treatment ever & 0.60 & 0.01 to 2.03 & \\
\hline Azathioprine at baseline & 0.51 & 0.03 to 2.47 & \\
\hline Chloroquine/Hydroxychloroquine at baseline & 1.01 & 0.32 to 2.67 & \\
\hline Warfarin at baseline & 1.45 & 0.34 to 4.27 & \\
\hline ASA at baseline & 1.54 & 0.55 to 3.70 & \\
\hline \multicolumn{4}{|l|}{ Autoantibodies against } \\
\hline dsDNA & 1.41 & 0.57 to 3.25 & \\
\hline
\end{tabular}




\section{Baseline predictors of the first ever cardiovascular event, page-adjusted Cox regression models}

\begin{tabular}{|c|c|c|c|}
\hline$C L \lg G$ & 2.57 & 1.13 to 6.13 & 0.02 \\
\hline$C L \lg M$ & 1.35 & 0.45 to 3.41 & \\
\hline$\beta_{2} \mathrm{GP} 1 \mathrm{lgG}$ & 2.57 & 1.13 to 5.99 & 0.02 \\
\hline Lupus anticoagulant & 1.10 & 0.40 to 2.63 & \\
\hline Any aPL & 4.90 & 1.76 to 17.72 & 0.002 \\
\hline SSA & 0.66 & 0.39 to 1.03 & \\
\hline SSB & 0.57 & 0.27 to 1.00 & 0.05 \\
\hline $\mathrm{Sm}$ & 1.21 & 0.48 to 2.29 & \\
\hline RNP & 1.60 & 0.76 to 2.87 & \\
\hline \multicolumn{4}{|c|}{ Markers of systemic inflammation } \\
\hline hs CRPt & 1.36 & 0.85 to 2.18 & \\
\hline Fibrinogent & 1.72 & 1.10 to 2.68 & 0.02 \\
\hline$\alpha-1$ antitrypsine & 1.49 & 1.01 to 2.18 & \\
\hline SAAt & 1.36 & 0.88 to 2.09 & \\
\hline IL $6 \dagger$ & 1.26 & 0.87 to 1.82 & \\
\hline C3 & 0.92 & 0.63 to 1.35 & \\
\hline C3d & 1.38 & 0.85 to 2.22 & \\
\hline $\mathrm{C} 4$ & 0.82 & 0.56 to 1.18 & \\
\hline \multicolumn{4}{|c|}{ Markers of endothelial activation } \\
\hline sVCAM-1† & 1.78 & 1.20 to 2.65 & 0.005 \\
\hline von Willebrand factort & 2.05 & 1.23 to 3.42 & 0.004 \\
\hline \multicolumn{4}{|c|}{ Markers of renal involvement } \\
\hline Creatininet & 1.17 & 0.74 to 1.85 & \\
\hline MDRD & 1.07 & 0.57 to 2.00 & \\
\hline Blood urea nitrogen & 1.15 & 0.75 to 1.77 & \\
\hline Pathological urine & 2.4 & 0.8 to 6.1 & \\
\hline \multicolumn{4}{|l|}{ Other biomarkers } \\
\hline Albumin(g/l) & 0.56 & 0.41 to 0.78 & 0.002 \\
\hline Homocystein $(\mu \mathrm{mol} / \mathrm{l}) \dagger$ & 0.79 & 0.52 to 1.21 & \\
\hline
\end{tabular}

Calculations were done using age-adjusted Cox regression. For continuous variables Hazard Ratio (HR) is given as risk per standard deviation, *For age HR is calculated per 10 years (HR/10 years). tcalculations were done on log transformed values. $P$ values $\leq 0.05$ are presented. $¥$ Infinite coefficient, due to no $A E$ in the diabetes group. SInfinite coefficient, due to all $A E$ in the arthritis group, confidence interval could thus not be determined for these two variables. Hypertension was defined as a systolic blood pressure $>140 \mathrm{~mm} \mathrm{Hg}$, and/or a diastolic blood pressure $>90 \mathrm{mmHg}$ and/or present treatment for hypertension. Hypercholesterolemia was defined as a total cholesterol level $>5.2 \mathrm{mmol} / \mathrm{L}$. $\beta_{2}$ GP-1 = beta2glykoprotein-1; $\beta_{2}$ GP-1 lgG or a positive lupus anticoagulant test;

any $\mathrm{PL}=$ positive antibody test against $\mathrm{CL} \lg$ or $\operatorname{lgM} ; \mathrm{ApoB} / \mathrm{Apo} \mathrm{A}=$ apolipoproteinB/A. Disease manifestations were defined according to the 1982 revised American College of Rheumatology (ACR) criteria for classification of SLE [19]; C = Complement factor; C3d = Complement factor 3 degradation products; $\mathrm{CL}=$ cardiolipin; dsDNA = doublestranded DNA; HDL = high density lipoprotein; hsCRP = high sensitivity $\mathrm{C}$ reactive protein; IL-6 = interleukin 6 ; LDL = low density lipoprotein;

MDRD = Estimated glomerular filtration rate using the Modification of Diet in Renal Disease (MDRD) formula [51]. Pathologic urine as defined by SLAM [20]; PL = phospholipid; $R N P=$ ribonucleoprotein; $S A A=$ serum amyloid $A ; S L A M=$ a measure of disease activity [20]; SLICC =a measure of cumulative disease damage [21]; Sm = Smith; SSA = Sjogrens syndrome A; SSB = Sjogrens syndrome B; sVCAM-1 = soluble vascular cell adhesion molecule 1. 
Table 3

\begin{tabular}{llll}
\hline Age at and type of first cardiovascular event & & & \\
\hline Type of cardiovascular event & Number of events & Median age at onset & Age range \\
\hline All cardiovascular events & 24 & 64.4 & 40.6 to 85.1 \\
Ischemic heart disease & 10 & 60.8 & 40.6 to 85.1 \\
Ischemic cerebrovascular disease & 6 & 65.7 & 49.9 to 83.9 \\
Ischemic peripheral vascular disease & 5 & 55.1 & 44.1 to 82.4 \\
Death due to cardiovascular disease & 3 & 64.7 & 58.1 to 68.6 \\
\hline
\end{tabular}

Ischemic heart disease = myocardial infarction or angina pectoris, ischemic cerebrovascular disease = cerebral infarction or transitory ischemic attacks, ischemic peripheral vascular disease = intermittent claudication or peripheral arterial thrombosis/embolus, death due to ischemic vascular disease = death due to myocardial infarction, heart failure, sudden death, cerebral infarction, generalized atherosclerosis as stated by death certificate.

tions with high levels of vWf. Plasma levels rise during acute coronary syndromes and high levels predict less favorable long time outcome in patients with established CVD, as recently reviewed by Spiel et.al [26]. Inflammatory cytokines can cause release of $\mathrm{vWf}$ from endothelial cells into the circulation where vWf has pro-thrombotic effects as it promotes aggregation of platelets [26]. SLE patients with subclinical atherosclerosis have increased vWf activity in the circulation [27] and vWf was furthermore induced by IgG from patients with SLE and thrombotic diseases [28] and by anti DNA antibodies in experimental studies [29]. The high activity of $\mathrm{vWf}$ in lupus $[27,30]$ may thus be attributable to both pro-inflammatory cytokines and to autoantibodies, and could directly contribute to the high incidence of CVE in SLE.

VCAM-1, an endothelial adhesion molecule is shed into the circulation when the endothelium is activated. In SLE, levels of sVCAM-1 are elevated and correlate with disease activity [31], renal manifestations [32] and aPL [33]. We have recently demonstrated that after adjustment for nephritis, high levels of sVCAM-1 discriminated SLE patients with manifest CVD from SLE patients free of CVD and population controls [34]. The present study extends these findings as we can report that high levels of sVCAM-1 predict future CVE, independently of aPLs. VCAM-1 has also been reported to predict poor longterm outcome in other patient groups at risk of CVD, that is, in hemodialysis patients [35], in patients with diabetic nephrop- athy [36] and in patients with manifest CAD [37]. Both vWf and VCAM-1 are markers of endothelial activation. Other studies have reported impaired endothelial function as measured by flow mediated dilatation [38] and that increased numbers of circulating apoptotic endothelial cells are present in SLE patients [39]. Taken together many studies report that endothelial perturbation occurs in SLE, and our results suggest that it precedes the first CVE.

In the general population, systemic inflammatory activity, often measured by CRP, is a well-documented risk factor for CVD. A similar role for fibrinogen, SAA and IL-6, has also been reported [40]. At baseline elevation of several inflammatory markers were more prevalent among patients who experienced their first CVE during follow-up, but after adjustment for age, only fibrinogen remained as a significant predictor. Fibrinogen is an important clotting protein, and high levels have been reported in SLE patients with a history of thrombotic disease [41]. CRP has previously been identified as a risk factor for arterial disease in SLE, but we were not able to replicate those results [8].

Patients with a positive test for any aPL had a higher risk of CVEs confirming previous findings by Toloza et.al [8]. Positive $\lg$ titers of $\mathrm{aCL}$, or $\beta_{2} \mathrm{GP} 1$, were predictive of CVE. However, $\operatorname{lgM} \mathrm{aCL}$ and $\mathrm{LAC}$ were not. Any positive aPL were more common in this study $(65 \%)$ than reported in most $[7,33,42]$ lupus

Table 4

Baseline predictors of the first ever cardiovascular event, multivariable-adjusted Cox regression

\begin{tabular}{llll}
\hline & Hazard Ratio & Confidence interval & $P$ \\
\hline Age $^{*}$ & 2.39 & 1.71 to 3.32 & $<0001$ \\
Thrombocytopenia & 0.35 & 0.08 to 0.77 & 0.005 \\
Any aPL & 4.23 & 1.56 to 14.83 & 0.003 \\
von Willebrand factort & 1.97 & 1.16 to 3.33 & 0.01 \\
\hline
\end{tabular}

Calculations were done using multivariable-adjusted Cox regression. *For age hazard ratio is calculated per 10 years (HR/10 years), for von Willebrand factor hazard ratio is given as risk per standard deviation, tcalculations were done on log transformed values. 
cohorts possibly indicating a low cut-off level at our laboratory in the mid 90's when baseline data were collected. It is therefore interesting to note that any aPL were only predictive of CVEs when we included the cut-off for positive tests. With a cut-off at medium titer, more in accordance with the definition of the anti-phospholipid syndrome (APS) [43], baseline aPLs were no longer significantly associated with future CVE (data not shown). This may be explained by limited power, as few patients had medium/high titer aPL, and by the fact that these patients were more often on anti-coagulation treatment. Nevertheless, our results suggest that also low titer aPL adds to the risk of CVEs in SLE patients.

We noted that subsets of patients with different lupus manifestations seemed to have a differentiated risk of CVE. Arthritis and pleuritis are SLE manifestations, often associated with a more pronounced acute phase response [15,44], and patients with these symptoms had a higher risk of developing a first CVE, as also reported by Mok et al [16]. Patients with a previous episode of venous occlusion, a major manifestation of APS [43], were more likely to present with a first CVE. They were also more likely to have any positive aPL (Odds Ratio $=$ $12.5,95 \% \mathrm{Cl}(1.6$ to 95.7$), P=0.0005)$. The observation that patients with previous thrombocytopenia, also associated with APS [43], were at lower risk of CVEs is new. Previous studies have demonstrated that thrombocytopenia is often associated with auto antibodies to platelet glycoproteins, but these antibodies have not been linked to thrombosis [45]. Hypothetically a low platelet count could confer a protective anti-coagulant effect, but this would need to be tested in larger samples. Another novel observation is that patients with photosensitivity and SSA/SSB antibodies, which often occur together, may be at lower CVD risk as compared to other SLE patients. Taken together, this study suggests that subgroups of SLE patients are not affected with the same high risk of CVEs. Larger cohort studies are needed to confirm these observations.

Besides age, smoking was the only traditional CVD risk factor which predicted CVEs in this study, this is in line with the results of Toloza et al [8] Lipid derangements including hypercholesterolemia, elevated ApoB/ApoA ratio, low HDL and hypertriglyceridemia, did not remain statistically significant after adjustment for age. Earlier studies are inconsistent with regard to the impact of blood lipids on CVD in SLE. Some have reported an association between manifest CVD and hypercholesterolemia $[46,47]$, hypertriglyceridemia $[48,49]$ or low HDL $[4,16]$ whereas this study and the prospective study from the LUMINA cohort did not find an association [8].

After adjusting for age, a lower estimated glomerular filtration rate at baseline was not predictive of presenting with a first CVE in this study. Hypoalbuminemia, positively associated both with markers of systemic inflammation and with loss of renal function (data not shown), was however a strong predictor. It was not entered into the multivariable-adjusted model because we regarded it as a proxy for both systemic inflammation and for renal disease. Its significance may however be useful since albumin measurements are inexpensive and commonly used in clinical practice.

The relatively small number of patients and events in the present study are limitations, which call for some caution, in particular with regard to subgroup analysis. It may also explain the lack of association with traditional CAD risk factors. The great majority of our patients were Caucasians of European origin, thus confirmation in other ethnic groups is needed before generalizing our results to SLE cohorts from other parts of the world. The detailed baseline information and the relatively long and almost complete follow-up including all deceased patients are strengths of the study. The fact that we only included the first ever CVE is a merit, but also a reason for the low number of events. Several patients eventually experienced additional events. Of note $9 / 24$ patients $(38 \%)$ who experienced a first CVE were dead when we closed the study in 2007. This figure further highlights the importance of conducting longitudinal prospective studies.

Due to the design of this study and the clinical definitions used for CVEs it was not possible to compare the incidence of CVEs in these lupus patients with the general population. However, other studies have shown that patients with SLE have a marked increased risk of CVD as compared to the general population $[2,15,50]$.

\section{Conclusions}

In conclusion this prospective study is the first to investigate lupus associated and CAD risk factors for the first ever CVE in patients with SLE. In addition to age, positive aPL, biomarkers indicating increased endothelial cell activity/damage, and absence of thrombocytopenia were independent predictors of CVEs. Our results indicate that activation of the endothelium and the coagulation system are important features in SLE related CVD. Furthermore, the risk of CVEs seems to differ between subgroups of SLE patients. How these findings influence and interact with the presence of premature atherosclerosis, not measured in this study, remains to be determined.

\section{Competing interests}

The authors declare that they have no competing interests.

\section{Authors' contributions}

$J G$ acquired, analyzed and interpreted the data and drafted the manuscript. IG OB, SP, SM and GZF acquired the data, KE coordinated and acquired the analysis of autoantibodies, JFS analyzed the data and drafted the manuscript, $\mathrm{LOH}$ and $\mathrm{AL}$ coordinated and acquired the laboratory data, IEL acquired the data ES conceived and designed the study, acquired, analyzed and interpreted the data and drafted the manuscript. All authors reviewed and approved the final manuscript. 


\section{Acknowledgements}

We are grateful to Elisabeth Bergh for statistical advice and to Jill Gustafsson, Eva Jemseby and Gull-Britt Almgren for management of patient cohorts and blood sampling.

The following sources of funding supported this study: Swedish HeartLung Foundation (ES), The Swedish Rheumatism Association (ES, IG), Centre of Gender related Medicine at Karolinska Institutet (ES), The King Gustaf V 80th Birthday Fund (ES, IG), The Swedish Society of Medicine (ES), The Åke Wiberg Foundation (ES), Alex and Eva Wallstöms Foundation (ES), Karolinska Institutet Foundations (ES, IG), Rheuma Research Foundation Margareta (IL), ALF funding from Stockholm County Council and Karolinska Institutet (IG, ES).

\section{References}

1. Bernatsky S, Boivin JF, Joseph L, Manzi S, Ginzler E, Gladman DD, Urowitz M, Fortin PR, Petri M, Barr S, Gordon C, Bae SC, Isenberg D, Zoma A, Aranow C, Dooley MA, Nived O, Sturfelt G, Steinsson K, Alarcon G, Senecal JL, Zummer M, Hanly J, Ensworth S, Pope J, Edworthy S, Rahman A, Sibley J, El-Gabalawy H, McCarthy T, et al:: Mortality in systemic lupus erythematosus. Arthritis Rheum 2006, 54:2550-2557.

2. Bjornadal L, Yin L, Granath F, Klareskog L, Ekbom A: Cardiovascular disease a hazard despite improved prognosis in patients with systemic lupus erythematosus: results from a Swedish population based study 1964-95. J Rheumatol 2004, 31:713-719.

3. Bruce IN, Urowitz MB, Gladman DD, Ibanez D, Steiner G: Risk factors for coronary heart disease in women with systemic lupus erythematosus: the Toronto Risk Factor Study. Arthritis Rheum 2003, 48:3159-3167.

4. Svenungsson $E$, Jensen-Urstad $K$, Heimburger $M$, Silveira $A$, Hamsten A, de Faire U, Witztum JL, Frostegard J: Risk factors for cardiovascular disease in systemic lupus erythematosus. Circulation 2001, 104:1887-1893.

5. Bessant R, Hingorani A, Patel L, MacGregor A, Isenberg DA, Rahman A: Risk of coronary heart disease and stroke in a large British cohort of patients with systemic lupus erythematosus. Rheumatology (Oxford) 2004, 43:924-929.

6. Esdaile JM, Abrahamowicz M, Grodzicky T, Li Y, Panaritis C, du Berger R, Cote R, Grover SA, Fortin PR, Clarke AE, Senecal JL: Traditional Framingham risk factors fail to fully account for accelerated atherosclerosis in systemic lupus erythematosus. Arthritis Rheum 2001, 44:2331-2337.

7. Nojima J, Masuda $Y$, Iwatani $Y$, Kuratsune $H$, Watanabe $Y$, Suehisa E, Takano T, Hidaka Y, Kanakura Y: Arteriosclerosis obliterans associated with anti-cardiolipin antibody/beta2-glycoprotein I antibodies as a strong risk factor for ischaemic heart disease in patients with systemic lupus erythematosus. Rheumatology (Oxford) 2008, 47:684-689.

8. Toloza SM, Uribe AG, McGwin G Jr, Alarcon GS, Fessler BJ, Bastian HM, Vila LM, Wu R, Shoenfeld Y, Roseman JM, Reveille JD: Systemic lupus erythematosus in a multiethnic US cohort (LUMINA). XXIII. Baseline predictors of vascular events. Arthritis Rheum 2004, 50:3947-3957.

9. Denny MF, Thacker S, Mehta H, Somers EC, Dodick T, Barrat FJ, McCune WJ, Kaplan MJ: Interferon-alpha promotes abnormal vasculogenesis in lupus: a potential pathway for premature atherosclerosis. Blood 2007, 110:2907-2915.

10. Westerweel PE, Luijten RK, Hoefer IE, Koomans HA, Derksen RH, Verhaar MC: Haematopoietic and endothelial progenitor cells are deficient in quiescent systemic lupus erythematosus. Ann Rheum Dis 2007, 66:865-870.

11. Frostegard J, Nilsson J, Haegerstrand A, Hamsten A, Wigzell $H$, Gidlund M: Oxidized low density lipoprotein induces differentiation and adhesion of human monocytes and the monocytic cell line U937. Proc Natl Acad Sci USA 1990, 87:904-908.

12. McMahon M, Grossman J, Skaggs B, Fitzgerald J, Sahakian L, Ragavendra N, Charles-Schoeman C, Watson K, Wong WK, Volkmann E, Chen W, Gorn A, Karpouzas G, Weisman M, Wallace DJ, Hahn BH: Dysfunctional proinflammatory high-density lipoproteins confer increased risk of atherosclerosis in women with systemic lupus erythematosus. Arthritis Rheum 2009, 60:2428-2437.

13. Svenungsson E, Gustafsson J, Leonard D, Sandling J, Gunnarsson I, Nordmark G, Jonsen A, Bengtsson AA, Sturfelt G, RantapaaDahlqvist S, Elvin K, Sundin U, Garnier S, Simard JF, Sigurdsson $S$, Padyukov L, Syvanen AC, Ronnblom L: A STAT4 risk allele is associated with ischemic cerebrovascular events and antiphospholipid antibodies in Systemic Lupus Erythematosus. Ann Rheum Dis 2009. doi:10.1136/ard.2009.115535

14. Cederholm A, Svenungsson E, Jensen-Urstad K, Trollmo C, Ulfgren AK, Swedenborg J, Fei GZ, Frostegard J: Decreased binding of annexin $v$ to endothelial cells: a potential mechanism in atherothrombosis of patients with systemic lupus erythematosus. Arterioscler Thromb Vasc Biol 2005, 25:198-203.

15. Jonsson $\mathrm{H}$, Nived $\mathrm{O}$, Sturfelt $\mathrm{G}$ : Outcome in systemic lupus erythematosus: a prospective study of patients from a defined population. Medicine (Baltimore) 1989, 68:141-150.

16. Mok CC, Tang SS, To CH, Petri M: Incidence and risk factors of thromboembolism in systemic lupus erythematosus: a comparison of three ethnic groups. Arthritis Rheum 2005, 52:2774-2782.

17. Roman MJ, Shanker BA, Davis A, Lockshin MD, Sammaritano L, Simantov R, Crow MK, Schwartz JE, Paget SA, Devereux RB, Salmon JE: Prevalence and correlates of accelerated atherosclerosis in systemic lupus erythematosus. N Engl J Med 2003, 349:2399-2406.

18. Westerweel PE, Luyten RK, Koomans HA, Derksen RH, Verhaar MC: Premature atherosclerotic cardiovascular disease in systemic lupus erythematosus. Arthritis Rheum 2007, 56:1384-1396.

19. Tan EM, Cohen AS, Fries JF, Masi AT, McShane DJ, Rothfield NF, Schaller JG, Talal N, Winchester RJ: The 1982 revised criteria for classification of systemic lupus erythematosus. Arthritis Rheum 1982, 25:1271-1277.

20. Liang MH, Socher SA, Roberts WN, Esdaile JM: Measurement of systemic lupus erythematosus activity in clinical research. Arthritis Rheum 1988, 31:817-825.

21. Gladman D, Ginzler E, Goldsmith C, Fortin P, Liang M, Urowitz M, Bacon P, Bombardieri S, Hanly J, Hay E, Isenberg D, Jones J, Kalunian K, Maddison P, Nived O, Petri M, Richter M, Sanchez-Guerrero J, Snaith M, Sturfelt G, Symmons D, Zoma A: The development and initial validation of the systemic lupus international collaborating clinics/American College of Rheumatology Damage index for Systemic lupus erythematosus. Arthritis Rheum 1996, 39:363-369.

22. Manzi S, Rairie JE, Carpenter AB, Kelly RH, Jagarlapudi SP Sereika SM, Medsger TA Jr, Ramsey-Goldman R: Sensitivity and specificity of plasma and urine complement split products as indicators of lupus disease activity. Arthritis Rheum 1996, 39:1178-1188.

23. Morange PE, Simon C, Alessi MC, Luc G, Arveiler D, Ferrieres J Amouyel P, Evans A, Ducimetiere P, Juhan-Vague I: Endothelial cell markers and the risk of coronary heart disease: the Prospective Epidemiological Study of Myocardial Infarction (PRIME) study. Circulation 2004, 109:1343-1348.

24. Thogersen AM, Jansson JH, Boman K, Nilsson TK, Weinehall $L$ Huhtasaari F, Hallmans G: High plasminogen activator inhibitor and tissue plasminogen activator levels in plasma precede a first acute myocardial infarction in both men and women: evidence for the fibrinolytic system as an independent primary risk factor. Circulation 1998, 98:2241-2247.

25. Whincup PH, Danesh J, Walker M, Lennon L, Thomson A, Appleby P, Rumley A, Lowe GD: von Willebrand factor and coronary heart disease: prospective study and meta-analysis. Eur Heart J 2002, 23:1764-1770.

26. Spiel AO, Gilbert JC, Jilma B: von Willebrand factor in cardiovascular disease: focus on acute coronary syndromes. Circulation 2008, 117:1449-1459.

27. de Leeuw K, Freire B, Smit AJ, Bootsma H, Kallenberg CG, Bijl M: Traditional and non-traditional risk factors contribute to the development of accelerated atherosclerosis in patients with systemic lupus erythematosus. Lupus 2006, 15:675-682.

28. Lindsey NJ, Dawson RA, Henderson Fl, Greaves M, Hughes P: Stimulation of von Willebrand factor antigen release by immunoglobulin from thrombosis prone patients with systemic lupus erythematosus and the anti-phospholipid syndrome. $\mathrm{Br}$ J Rheumatol 1993, 32:123-126. 
29. Lai KN, Leung JC, Lai KB, Lai FM, Wong KC: Increased release of von Willebrand factor antigen from endothelial cells by antiDNA autoantibodies. Ann Rheum Dis 1996, 55:57-62.

30. Ferro D, Pittoni V, Quintarelli C, Basili S, Saliola M, Caroselli C, Valesini G, Violi F: Coexistence of anti-phospholipid antibodies and endothelial perturbation in systemic lupus erythematosus patients with ongoing prothrombotic state. Circulation 1997, 95:1425-1432.

31. Spronk PE, Bootsma H, Huitema MG, Limburg PC, Kallenberg CG: Levels of soluble VCAM-1, soluble ICAM-1, and soluble Eselectin during disease exacerbations in patients with systemic lupus erythematosus (SLE); a long term prospective study. Clin Exp Immunol 1994, 97:439-444.

32. Ikeda Y, Fujimoto T, Ameno M, Shiiki H, Dohi K: Relationship between lupus nephritis activity and the serum level of soluble VCAM-1. Lupus 1998, 7:347-354.

33. Farzaneh-Far A, Roman MJ, Lockshin MD, Devereux RB, Paget SA, Crow MK, Davis A, Sammaritano L, Levine DM, Salmon JE: Relationship of antiphospholipid antibodies to cardiovascular manifestations of systemic lupus erythematosus. Arthritis Rheum 2006, 54:3918-3925.

34. Svenungsson E, Cederholm A, Jensen-Urstad K, Fei GZ, de Faire $\mathrm{U}$, Frostegard J: Endothelial function and markers of endothelial activation in relation to cardiovascular disease in systemic lupus erythematosus. Scand J Rheumato/ 2008, 37:352-359.

35. Papagianni A, Dovas S, Bantis C, Belechri AM, Kalovoulos M, Dimitriadis C, Efstratiadis G, Alexopoulos E, Memmos D: Carotid atherosclerosis and endothelial cell adhesion molecules as predictors of long-term outcome in chronic hemodialysis patients. Am J Nephrol 2008, 28:265-274.

36. Wu T, McGrath KC, Death AK: Cardiovascular disease in diabetic nephropathy patients: cell adhesion molecules as potential markers? Vasc Health Risk Manag 2005, 1:309-316.

37. Blankenberg S, Rupprecht HJ, Bickel C, Peetz D, Hafner G, Tiret $\mathrm{L}$, Meyer J: Circulating cell adhesion molecules and death in patients with coronary artery disease. Circulation 2001, 104:1336-1342.

38. Lima DS, Sato El, Lima VC, Miranda F Jr, Hatta FH: Brachial endothelial function is impaired in patients with systemic lupus erythematosus. J Rheumatol 2002, 29:292-297.

39. Rajagopalan S, Somers EC, Brook RD, Kehrer C, Pfenninger D, Lewis E, Chakrabarti A, Richardson BC, Shelden E, McCune WJ, Kaplan MJ: Endothelial cell apoptosis in systemic lupus erythematosus: a common pathway for abnormal vascular function and thrombosis propensity. Blood 2004, 103:3677-3683.

40. Willerson JT, Ridker PM: Inflammation as a cardiovascular risk factor. Circulation 2004, 109:II2-II10.

41. Ames PR, Alves J, Pap AF, Ramos P, Khamashta MA, Hughes GR: Fibrinogen in systemic lupus erythematosus: more than an acute phase reactant? J Rheumatol 2000, 27:1190-1195.

42. Sturfelt G, Eskilsson J, Nived O, Truedsson L, S V: Cardiovascular Disease in Systemic Lupus Erythematosus, A Study of $\mathbf{7 5}$ Patients from a Defined Population. Medicine 1992, 71:216-223.

43. Miyakis S, Lockshin MD, Atsumi T, Branch DW, Brey RL, Cervera R, Derksen RH, PG DEG, Koike T, Meroni PL, Reber G, Shoenfeld $Y$, Tincani A, Vlachoyiannopoulos PG, Krilis SA: International consensus statement on an update of the classification criteria for definite antiphospholipid syndrome (APS). J Thromb Haemost 2006, 4:295-306.

44. Spronk PE, ter Borg EJ, Kallenberg CG: Patients with systemic lupus erythematosus and Jaccoud's arthropathy: a clinical subset with an increased $\mathrm{C}$ reactive protein response? Ann Rheum Dis 1992, 51:358-361.

45. Galli M, Daldossi M, Barbui T: Anti-glycoprotein Ib/IX and Ilb/ IIla antibodies in patients with antiphospholipid antibodies. Thromb Haemost 1994, 71:571-575.

46. Manzi S, Meilahn EN, Rairie JE, Conte CG, Medsger TA Jr, JansenMcWilliams L, D'Agostino RB, Kuller LH: Age-specific incidence rates of myocardial infarction and angina in women with systemic lupus erythematosus: comparison with the Framingham Study. Am J Epidemiol 1997, 145:408-415.

47. Petri M, Pereez-Gutthann S, Spence D MC H: Risk Factors for coronary Artery Disease in Patients With Systemic Lupus Erythematosus. The American Journal of Medicine 1992, 93:513-519.
48. Bessant $R$, Duncan $R$, Ambler G, Swanton J, Isenberg DA, Gordon $C$, Rahman A: Prevalence of conventional and lupus-specific risk factors for cardiovascular disease in patients with systemic lupus erythematosus: A case-control study. Arthritis Rheum 2006, 55:892-899.

49. Svenungsson E, Fei GZ, Jensen-Urstad K, de Faire U, Hamsten A, Frostegard J: TNF-alpha: a link between hypertriglyceridaemia and inflammation in SLE patients with cardiovascular disease. Lupus 2003, 12:454-461.

50. Hak AE, Karlson EW, Feskanich D, Stampfer MJ, Costenbader KH: Systemic lupus erythematosus and the risk of cardiovascular disease: results from the nurses' health study. Arthritis Rheum 2009, 61:1396-1402.

51. Levey AS, Bosch JP, Lewis JB, Greene T, Rogers N, Roth D: A more accurate method to estimate glomerular filtration rate from serum creatinine: a new prediction equation. Modification of Diet in Renal Disease Study Group. Ann Intern Med 1999, 130:461-470. 